\title{
AKAD QARDH DALAM LEMBAGA KEUANGAN SYARIAH
}

\author{
Fasiha \\ Fakultas Ekonomi dan Bisnis Islam IAIN Palopo \\ fasihaiainpalopo@gmail.com
}

\begin{abstract}
Abstrak
Lembaga Keuangan merupakan lembaga yang memiliki peran penting dalam mengelolah dana umat. seperti halnya, perbankan Syariah yang menyediakan berbagai macam produk yang ditawarkan kepada umat. Tulisan ini akan mengkaji salah satu produk lembaga keuangan syariah yakni Qardh. Pemahasaan tulisan ini menekankan pada Penerapan Akad Qardh dalam Lembaga Keuangan Syari'ah. Hasil penelitian menunjukkan bahwa penerapan akad qardh dalam LKS harus mengikuti rukun dan syarat qardh, akad qardh dan shigat qardh. LKS sebagai wadah dalam menyalurkan dana umat. Seperti: zakat, infaq, dan shadaqah dalam bentuk Qard. Qard adalah pinjaman tanpa keuntungan. LKS memberi penilaian kelayakan kepada nasabah. LKS tidak boleh menarik keuntungan dalam kontrak. Dalam qard. nasabah mengembalikan dana sebesar pinjaman ke pada LKS.
\end{abstract}

Kata Kunci: Qardh, LKS, Bank Syariah

\section{Abstract}

Financial institutions involved in fund management. like, Islamic banking that provides a wide range of products offered to people. This paper will explore one product of Islamic financial institutions that is Qardh. This understanding begins with the Implementation of Qardh Agreement at Sharia Financial Institutions. The results show that the implementation of the contract in the LKS should be in accordance with the terms and conditions of qardh, qardh contract and shigat qardh. LKS as a container in channeling public funds. Such as: zakat, infaq, and shadaqah in Qard form. Qard is a non-profit loan. LKS provides eligibility to customers. LKS should does not gain any profit in the contract. In qard, the customer returns the loan in accordance with the loan amount to the LKS

Keywords: Qardh, Islamic financial

\section{A. Pendahuluan}

Seiring dengan cepatnya akselerasi wacana ekonomi Syari'ah di tengah-tengah masyarakat, fiqhi muamalat menjadi bahan diskusi terus menerus. Persoalan yang selalu mengemuka adalah apakah fiqhi muamalat persoalan hukum ataukah persoalan ekonomi. Di dalam muamalat dibahas tentang berbagai macam tehnis transaksi dalam 
hubungannya dengan aktifitas melakukan produksi, distribusi, dan konsumsi, maka muamalah sarat dengan isu-isu ekonomi, namun di sisi lain dalam muamalah juga digariskan tentang berbagai ketentuan dan persyaratan yang harus dipenuhi agar sebuah aktifitas produksi, distribusi dan konsumsi tersebut dianggap sah, maka muamalah sarat dengan isu-isu hukum. Maka tidak salah jika isu-isu muamalah memang terkandung makna ekonomi dan hukum sekaligus. ${ }^{1}$

Dengan membaca hukum-hukum syara' yang menyangkut masalah ekonomi tersebut, nampaklah bahwa Islam telah memecahkan masalah bagaimana agar manusia bisa memanfaatkan kekayaan yang ada. Dan inilah yang sesungguhnya, menurut pandangan Islam, dianggap sebagai masalah ekonomi bagi suatu masyarakat. Sehingga ketika membahas ekonomi, Islam hanya membahas masalah bagaimana cara memperoleh kekayaan, masalah mengelolah kekayaan yang dilakukan oleh manusia, serta cara mendistribusikan kekayaan tersebut di tengah-tengah mereka. Atas dasar inilah, maka hukum-hukum yang menyangkut masalah ekonomi dibangun di atas tiga kaidah, yaitu kepemilikan (property), pengelolaan kepemilikan, dan distribusi kekayaan di tengah-tengah manusia. ${ }^{2}$

Lembaga Keuangan merupakan lembaga yang memiliki peranan penting dalam mengelolah dana umat, seperti halnya dengan perbankan Syariah yang menyediakan berbagaimana macam produk yang ditawarkan kepada umat. Produk-produk bank syariah tidak terlepas dari jenis akad yang digunakan. Jenis akad yang digunakan oleh suatu produk biasanya melekat pada nama produk tersebut. Dalam makalah ini penulis akan mengkaji salah satu produk lembaga keuangan syariah yakni Qardh, dalam penulisan tersebut penulis penekankan pada Penerapan Akad Qardh dalam Lembaga Keuangan Syari'ah.

\footnotetext{
${ }^{1}$ M. Yazid Afandi , Fiqhi Muamalah dana Implementasinya dalam Lembaga Keuangan Syari'ah (Yogyakarta; Logung Pustaka, 2009), h. 1

2 Taqyuddin An-Nabhani, An-Nidlam Al-Iqtishadi An-Nabhani, (terj) Membangun Sistem Ekonomi Alternatif "perspektif Islam”" (Surabaya; Risalah Gusti, 1996), h.61
} 


\section{B. Pembahasan}

Qardh menurut bahasa adalah قرض - الإقراضyang artinya pinjamanpeminjaman. ${ }^{3}$, atau Qiradh berarti Al Qith'u (cabang) atau potongan ialah harta yang diberikan seseorang pemberi qiradh kepada orang yang diqiradhkan untuk kemudian dia memberikannya setelah mampu ${ }^{4}$, pengalihan hak milik harta atas harta ${ }^{5}$ jadi $a l$ Qardh adalah pemberian harta kepada orang lain yang dapat ditagih atau diminta kembali atau dengan kata lain meminjamkan tanpa mengharapkan imbalan. Dalam literature fiqhi klasik, qardh dikategorikan dalam aqd tathawwui atau akad saling membantu dan bukan transaksi komersial ${ }^{6}$.

Qardh secara bahasa, berarti Al-Qath'u: pemotongan. Harta yang disodorkan kepada orang yang berutang disebut Qardh, karena merupakan 'potongan' dari harta orang yang memberikan utang. Ini termasuk penggunaan isim mashdar (gerund = non verbal) untuk menggantikan ism maf ul.

Secara syar'i, menurut Hanafi, adalah harta yang memiliki kesepadanan yang anda berikan untuk anda tagih kembali, atau dengan kata lain: suatu transaksi yang dimaksud untuk memberikan harta yang memiliki kesepadanan kepada orang lain untuk dikembalikan yang sepadan dengan itu. ${ }^{7}$

Memberi hutang merupakan kebaikan yang dianjurkan, karena, hal itu berarti membantu menunaikan hajat orang yang membutuhkan. Semakin kebutuhan itu mendesak dan amalnya semakin ikhlas karena Allah, maka pahalanya semakin besar. Memberi hutang ibarat bersedekah dengan setengahnya. ${ }^{8}$

${ }^{3}$ Ahmad Warsun Munawwir, Kamus Al-Munawwir: Arab-Indonesia (Surabaya: Pustaka Progressif, 2002), h. 1191

${ }^{4}$ Sayid Sabiq, Fikih Sunnah (Kuala Lumpur; Victori A, 1990), h. 129

${ }^{5}$ Wahbah Zulhili, Al-Fiqhu Al Islam wa Adillatuhu. terj. (Jakarta; PT. BMI, 1999) h. 1/11

${ }^{6}$ Muhammad Syafi'I Antonio, Bank Syariah dari Teori ke Praktik. (Jakarta; Gema Insani Press, 2001), h.131

${ }^{7}$ Wahbah Zulhili, Al-Fiqhu Al Islam wa Adillatuhu., h. 2/11

${ }^{8}$ Syaikh Muhammad bin Ibrahim bin Abdullah At-Tuwaijiri, Ensiklopedi Islam Kaffah (Surabaya; Pustaka Yassir, 2009). h. 919 
1. Dasar Hukum

QS. Al-Hadiid: 11

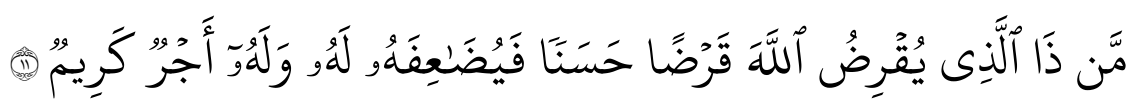

Terjemah:

Siapakah yang mau meminjamkan kepada Allah pinjaman yang baik, Maka Allah akan melipat-gandakan (balasan) pinjaman itu untuknya, dan Dia akan memperoleh pahala yang banyak.

QS. An-Naml; 89

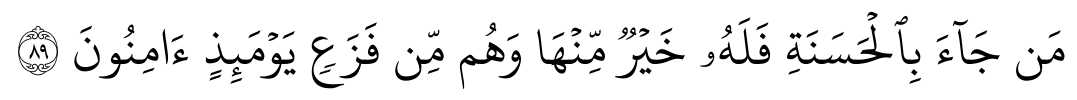

Terjemah:

Barangsiapa yang membawa kebaikan, Maka ia memperoleh (balasan) yang lebih baik dari padanya, sedang mereka itu adalah orang-orang yang aman tenteram dari pada kejutan yang dahsyat pada hari itu.

Al-Hadis

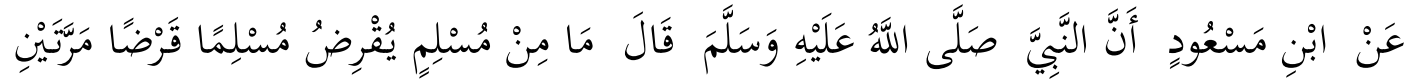

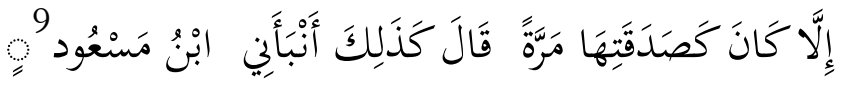

Artinya;

Ibnu Mas'ud meriwayatkan bahwa Nabi Saw, berkata, "Bukan seorang muslim (mereka) yang meminjamkan muslim (lainnya) dua kali kecuali yang satunya adalah (senilai) sedekah (HR. Ibnu Majah no. 2420, Kitab al-Ahkam)

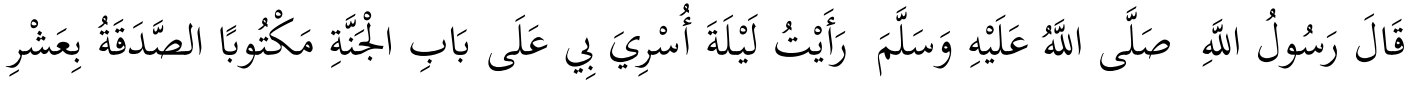

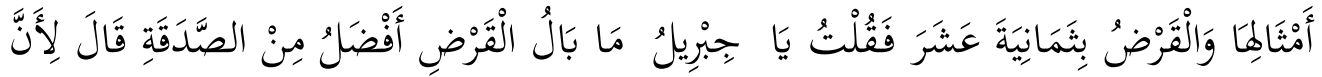

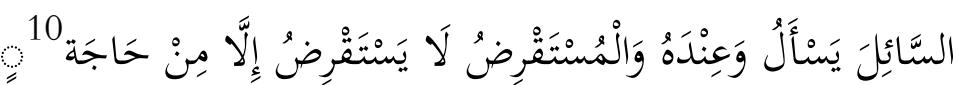

Artinya;

Bahwa Rasulullah berkata, "Aku melihat pada waktu malam di-Isra-kan, pada pintu surge tertulis: sedekah dibalas sepuluh kali lipat dan qardh delapan belas kali. Aku bertanya, Wahai Jibril, mengapa qardh lebih utama dari sedekah. Ia menjawab, 'karena peminta-minta sesuatu dana

\footnotetext{
${ }^{9}$ Muslim Explorer (Islamic Softwere for Al-Quran and Hadits Studies), v.7. Ibnu Majah no. 2420, Kitab al-Ahkam

${ }^{10}$ Muslim Explorer,. Ibnu Majah no. 2421, Kitab al-Ahkam
} 
ia punya, sedangkan yang meminjam tidak akan meminjam kecuali karena keperluan. (HR. Ibnu Majah no. 2421, Kitab al-Ahkam)

2. Rukun dan Syarat Qardh

Rukun harus ada dalam setiap akad untuk terjadinya akad, ${ }^{11}$ karena rukun adalah sesuatu yang menjadi tegaknya dan adanya sesuatu, dan rukun bersifat internal (dakhiliy) dari sesuatu yang ditegakkanya. ${ }^{12}$

Rukun Qardh ada empat yakni ${ }^{13}$;

a. Muqridh; orang yang mempunyai barang-barang untuk diutangkan

b. Mustaridh; orang yang mempunyai utang

c. Muqtaradh; obyek yang berutang

d. Sighat akad; ijab Kabul

Yang disyaratkan harus orang yang cakap untuk melakukan tindakan hukum dan barang yang dihutangkan disyaratkan berbentuk barang yang dapat diukur/ diketahui jumlah maupun nilainya. Disyaratkannya hal ini agar pada waktu pembayaran tidak menyulitkan, sebab harus sama jumlah/ nilainya dengan jumlah/ nilai barang yang diterima. $^{14}$

Adapun syarat yang terkait dengan akad qardl, dirinci berdasarkan rukun akad qardl di atas ${ }^{15}$;

a. Syarat Aqidain (muqridl dan muqtaridl)

1) Ahliyatu al-tabarru (layak bersosial); adalah orang yang mampu mentasarufkan hartanya sendiri secara mutlak dan bertanggung jawab. Dalam pengertian ini anak kecil belum mempunyai kewenangan untuk mengelolah harta, orang cacat mental dan budak tidak boleh melakukan akad qardl.

\footnotetext{
${ }^{11}$ Syamsul Anwar, Hukum Perjanjian Syariah: Studi tentang Teori Akad dalam Fikih Muamalat (Jakarta; PT. Grafindo Persada, 2007), h.96

${ }^{12}$ Ghufron A. Mas'adi, Fiqhi Muamalah Kontekstual (Jakarta; Raja Grafindo Persada, 2002), h. 78

${ }^{13}$ Sayid Sabiq, Fikih Sunnah, h.142-143

${ }^{14}$ Chairumah Pasaribu \& Suhrawadi K. Lubis, Hukum Perjanjian dalam Islam (Jakarta; Sinar Grafika, 1996), h. 137

${ }^{15}$ Sayid Sabiq, Fikih Sunnah, h.143
} 
2) Tanpa ada paksaan; bahwa muqridl dalam memberikan hutangnya tidak dalam tekanan dan paksaan orang lain, demikian juga sebaliknya. Keduanya melakukan secara suka rela.

b. Syarat Muqtaradl (barang yang menjadi obyek qardl), adalah barang yang bermanfaat dan dapat dipergunakan. Barang yang tidak berguna secara syar'i tidak bisa ditransaksikan

c. Syarat Shighat; Ijab qabul menunjukkan kesepakatan kedua bela pihak, dan qardl tidak boleh mendatangkan manfaat bagi muqridl. Demikian juga shighat tidak mensyarakatkan qardl bagi akad lainnya.

Sebagaimana dalam al_Qur'an surat an-Nisaa: 29 sebagai berikut:

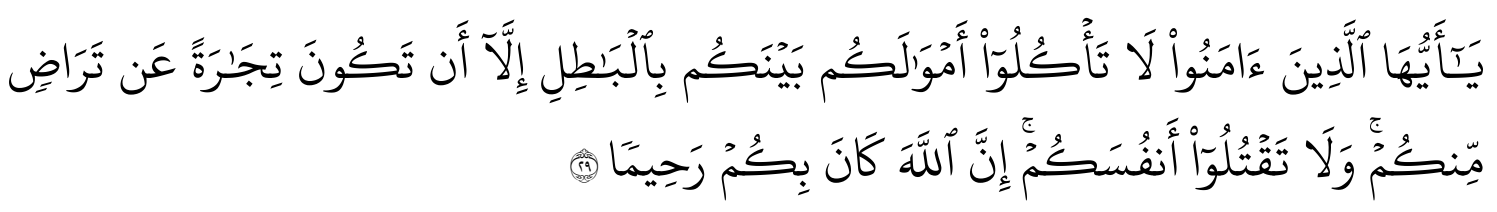

Terjemah:

Hai orang-orang yang beriman, janganlah kamu saling memakan harta sesamamu dengan jalan yang batil, kecuali dengan jalan perniagaan yang Berlaku dengan suka sama-suka di antara kamu.

Menurut Wahbah zulhili; qard diperbolehkan dengan dua syarat ${ }^{16}$ :

a. Tidak mendatangkan keuntungan, jika keutungan tersebut untuk muqridh, maka para ulama sudah bersepakat bahwa ia tidak diperbolehkan. Karena ada larangan dari syariat dan karena sudah keluar dari jalur kebajikan. Jika untuk muqtaridh, maka diperbolehkan. Dan jika untuk mereka berdua, tidak boleh, kecuali jika sangat membutuhkan, akan tetapi ada perbendaan pendapat dalam mengartikan "sangat dibutuhkan"

b. Tidak dibarengi dengan transaksi lain, seperti jual beli dan lainnya

Adapun hadiah dari pihak muqtaridh, maka menurut Malikiyah, tidak boleh diterima oleh muqridh karena mengarah pada tambahan atas pengunduran sedangka jumhur ulama memperbolehkan, jika bukan merupakan kesepakatan ${ }^{17}$

3. Akad Qardh dan Shigat Qardh

\footnotetext{
${ }^{16}$ Wahbah Zulhili, Al-Fiqhu Al Islam wa Adillatuhu, h. 10/11

${ }^{17}$ Ibid, h. 10/11
} 
Dalam hukum Islam untuk terbentuknya suatu akad (perjanjian) yang sah dan mengikat haruslah dipenuhi 1) rukun akad dan 2) syarat akad. Syarat akad dibedakan menjadi empat yaitu ${ }^{18}$ :

a. Syarat terbentuknya akad (syuruth al-in'iqad)

b. Syarat keabsahan akad (syuruth ash-shihhah)

c. Syarat berlakunya akibat hukum akad (syurutha-nafadz)

d. Syarat mengikatnya akad (syuruth al-luzum)

Akad juga terbentuk karena adanya unsur-unsur atau rukun-rukun yang membentuknya, rukun yang membentuk akad itu ada empat, yaitu ${ }^{19}$ :

a. Para pihak yang membuat akad (al-aqidan)

b. Pernyataan kehendak para pihak (shigatul-aqd)

c. Objek akad (mahallul-aqd), dan

d. Tujuan akad (maudhu' al-aqd)

Menurut Sayid Sabiq, Akad Qiradh adalah akad Tamlik, karena itu tidak sah kecuali dari orang yang boleh (secara hukum) menggunakan harta dan tidak sah kecuali dengan ijab dan kabul seperti akad jual beli dan hibah. Akad dinyatakan sah dengan lafaz qardh, salaf dan semua lafaz yang berpengertian sama. Menurut mazhab Maliki, pemilikan terjadi dengan akad (saja) sekali pun serah terima harta belum terjadi dan semua qiradh yang membuahkan bunga adalah riba dalam kaedah fiqhi ${ }^{20}$;

"Semua bentuk Qardh yang membuahkan bunga adalah riba"

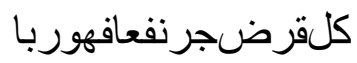

Para ulama' fiqhi sepakat bahwa akad qard dikategorikan akad Ta'awuniy (akad saling tolong menolong), bukan transaksi komersial. Maka dalam perbankan syariah akad ini dapat digunakan untuk menjalankan kegiatan sosial bank syari'ah. Yaitu memberi pinjaman murni kepada orang yang membutuhkan tanpa dikenakan apapun. Meskipun demikian nasabah tetap berkewajiban untuk mengembalikan dana tersebut kecuali jika bank mengihklaskannya ${ }^{21}$.

\footnotetext{
${ }^{18}$ Syamsul Anwar, Hukum Perjanjian Syariah, h.95

${ }^{19}$ ibid, h. 96

${ }^{20}$ Sayid Sabiq, Fikih Sunnah. h.131 dan lihat, Wahbah Zulhili, Al-Fiqhu Al Islam wa Adillatuhu, h. $4 / 11$

${ }^{21}$ M. Yazid Afandi, M.Ag, Fiqhi Muamalah, h. 144
} 


\section{Pembayaran Hutang 22}

a. Pembayaran utang dengan barang yang tidak sama jenisnya

Dalam sebuah riwayat dikatakan bahwa Umar mengatakan boleh. Beliau berkata tentang seorang laki-laki yang meminjam dinar kepada orang lain, apa boleh dia menerima pembayaran dengan dirham? Umar ra. Berkata: "Jika dirham itu sama harga/nilainya dengan dinar yang dipinjam, maka bayarlah

b. Syarat adanya manfaat yang harus diterima oleh orang yang menghutangi Tidak boleh memberikan syarat, keharusan adanya harta atau manfaat yang lain yang harus diterima oleh orang yang memberi hutang dari orang yang berhutang, karena itu adalah riba dan tidak halal dalam Islam

c. Sebaik-baik pembayaran

Jika orang yang menghutangi tidak memberikan syarat adanya tambahan atau manfaat, lantas orang yang hutang memberikan sesuatu kepadanya, maka boleh dia mengambilnya. Karena ini termasuk sebaik-baik pembayaran

Diriwayatkan dari Ibnu Sirin bahwa Ubay bin Ka'ab meminjam kepada Umar ra. Sepuluh ribu. Lalu ia memberikan buah-buahan yang paling bagus di Madinah kepada Umar ra., tapi dikembalikan oleh Umar ra., kemudian Ubay menyakinkannya: "tidak ada larangan pemberian saya ini”. Akhirnya Umar mau menerima buah-buahan pemberian Ubay tersebut

5. Qardh dalam Lembaga Keuangan Syariah

Satu-satunya akad berbentuk pinjaman yang diterapkan dalam perbankan syariah adalah Qardh dan turunanya Qardhul Hasan. Karena bunga dilarang dalam Islam, maka pinjaman Qardh maupun Qardhul Hasan merupakan pinjaman tanpa bunga. Lebih khusus lagi, pinjaman Qardhul Hasan merupakan pinjaman kebajikan yang tidak bersifat komersial. ${ }^{23}$ Sehingga disebut akad Ta'awuniy (akad saling tolong menolong).

\footnotetext{
${ }^{22}$ Muhammad Rawwas Qal'ahji, Ensiklopedi Fiqhi Umar bin Khathab ra (Jakarta; PT Raja Grafindo Persada, 1999), h. 59, bandingkan dengan Syaikh Muhammad bin Ibrahim bin Abdullah AtTuwaijiri, Ensiklopedi Islam Kaffah (Surabaya; Pustaka Yassir, 2009). h. 920

${ }^{23}$ Ascarya, Akad dan Produk Bank Syariah (Jakarta; PT. Raja Grafindo Persada, 2008), h.46
} 
Berdasarkan fatwa DSN, maka yang menjadi pertimbangan DSN menetapkan alQard al-Hasan sebagai sebuah sistem perekonomian yang sah menurut syari'ah adalah: ${ }^{24}$

a. Lembaga Keuangan Syari'ah (LKS) disamping sebagai lembaga komersial, harus dapat berperan sebagai lembaga sosial yang dapat meningkatkan perekonomian secara maksimal

b. Sebagai salah satu sarana peningkatan perekonomian yang dapat dilakukan oleh LKS adalah penyaluran dana melalui prinsip al-Qard, yakni suatu akad pinjaman kepada nasabah dengan ketentuan bahwa nasabah wajib mengembalikan dana yang diterimanya kepada LKS pada waktu yang telah disepakati oleh LKS dengan nasabah.

c. Akad tersebut sesuai dengan syari'ah Islam, DSN memandang perlu mendapatkan fatwa tentang akad al-qard untuk dijadikan pedoman oleh LKS

Qard biasanya digunakan untuk menyediakan dana talangan kepada nasaba prima dan untuk menyumbang sektor usaha kecil/ mikro atau membantu sektor sosial ${ }^{25}$. Sifat qardh tidak memberikan keuntungan finansial, karena itu, pendanaan qardh dapat diambil menurut kategori berikut; ${ }^{26}$

a. Al-Qardh yang diperlukan untuk membantu keuangan nasabah secara cepat dan berjangka pendek. Talangan diatas dapat diambilkan dari modal bank

b. Al-Qardh yang diperlukan untuk usaha sangat kecil dan keperluan sosial, dapat bersumber dari dana zakat, infak, dan sedekah. Disamping sumber dana umat, para praktisi perbankan syariah, demikian juga ulama, melihat adanya sumber dana lain yang dapat dialokasikan untuk qardh al-hasan, yaitu pendapatanpendapatan yang diragukan, seperti jasa nostro di bank koresponden yang konvensional, bunga atas jaminan L/C di bank asing, dan sebagainya. Salah satu pertimbangan pemanfaatan dana-dana ini adalah kaidah akhaff dhararain (mengambil mudharat yang lebih kecil).

\footnotetext{
${ }^{24}$ Brifecase Books Edukasi Profesional Syari'ah, Fatwa-Fatwa Ekonomi Syari'ah Kontemporer (Jakarta: Renaisan, 2005), h. 55

${ }^{25}$ Ascarya, Akad dan Produk Bank Syariah, h. 47

${ }^{26}$ Muhammad Syafi'I Antonio, Bank Syariah, 133
} 
Skema al-Qardh

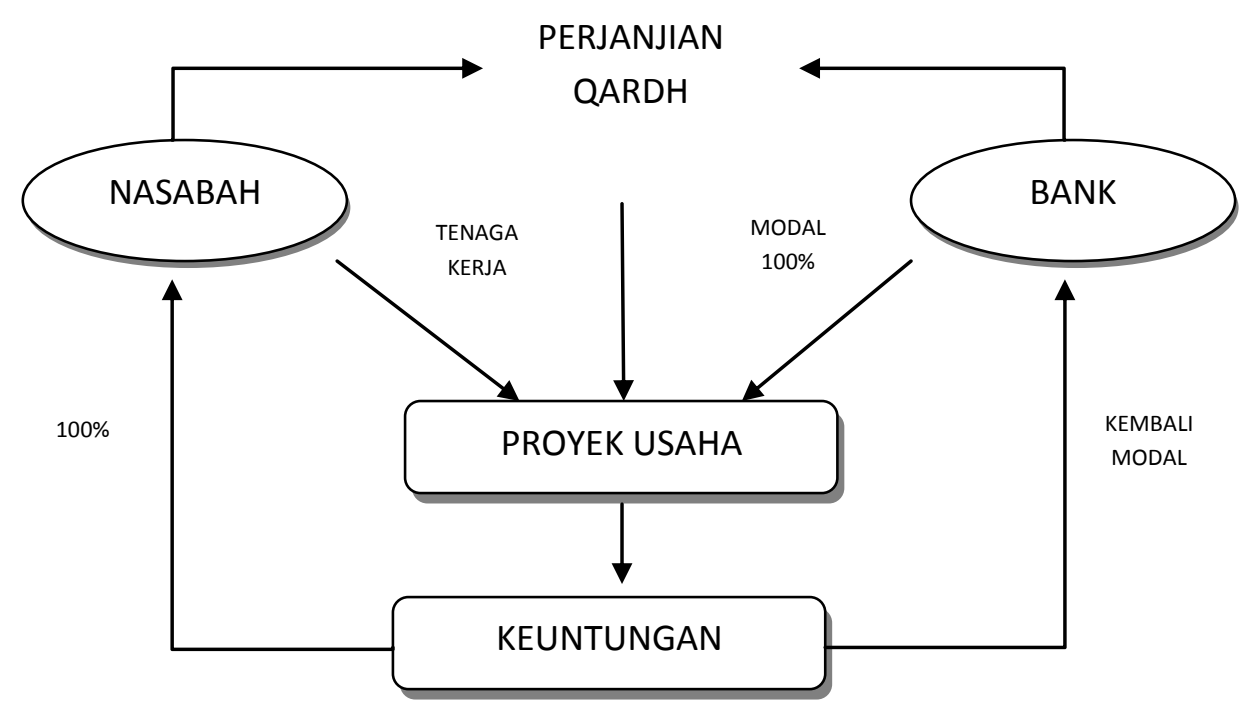

Dari skema di atas maka dapat digambarkan bahwa LKS hanya sebagai wadah dalam menyalurkan dana umat, baik berupa zakat, infaq, dan shadaqah dalam bentuk Qard yakni pinjaman tanpa adanya keuntungan. LKS dalam hal ini memberikan penilaian yang berhak memperoleh pinjaman qard dan LKS tidak boleh menarik keuntungan yang diperjanjikan. Dalam qard ini nasabah wajib mengembalikan dana kepada LKS sebesar pinjaman yang telah diperoleh dalam artian LKS meneriam kembalian modal dari nasabah

Dengan demikian hal-hal yang perlu diperhatikan dalam pembiayaan qard alhasan yakni ${ }^{27}$;

a. Qard al-hasan adalah pembiayaan yang diberikan kepada nasabah (muqtarid) yang membutuhkan

b. Nasabah qard al-hasan wajib mengembalikan jumlah pokok yang diterima pada waktu yang telah disepakati

c. Biaya adminitrasi dibebankan kepada nasabah

d. Nasabah qard hasan dapat memberikan tambahan (sumbangan) dengan sukarela kepada LKS selama tidak diperjanjikan dalam akad

\footnotetext{
${ }^{27}$ Brifecase Books Edukasi Profesional Syari'ah, h. 55-56
} 
e. Jika nasabah tidak dapat mengembalikan sebagian atau seluruh kewajiban pada saat yang telah disepakati dan LKS telah menentukan ketidakmampuannya maka LKS dapat;

f. Memperpanjang jangka waktu pengembalian

g. Menghapus (write off) sebagian atau seluruh kewajiban

\section{Kesimpulan}

Dalam perbankan syari'ah, akad qaedh dijalankan untuk fungsi sosial bank. Dananya diambil dari dana zakat, infak, shadaqah atau diambilkan dari sebagian keuntungan bank. Akad qardh disebut akad Ta'awuniy (akad saling tolong menolong). Qardh lebih efektif jika pinjaman yang diberikan adalah dipergunakan untuk kepentingan produktif, bukan untuk konsumsi. Dalam pelaksanaannya, LKS harus mengikuti rukun dan syarat qardh, akad qardh dan shigat qardh.

\section{Daftar Pustaka}

Afandi, M. Yazid. Fiqhi Muamalah dana Implementasinya dalam Lembaga Keuangan Syari'ah. Yogyakarta; Logung Pustaka, 2009.

An-Nabhani, Taqyuddin. An-Nidlam Al-Iqtishadi An-Nabhani, (terj) Membangun Sistem Ekonomi Alternatif “perspektif Islam”. Surabaya; Risalah Gusti, 1996.

Antonio, Muhammad Syafi'I. Bank Syariah dari Teori ke Praktik. Jakarta; Gema Insani Press, 2001.

Anwar, Syamsul. Hukum Perjanjian Syariah: Studi tentang Teori Akad dalam Fikih Muamalat. Jakarta; PT. Grafindo Persada, 2007. 2008 .

Ascarya, Akad dan Produk Bank Syariah. Jakarta; PT. Raja Grafindo Persada,

Brifecase Books Edukasi Profesional Syari'ah, Fatwa-Fatwa Ekonomi Syari'ah Kontemporer. Jakarta: Renaisan, 2005.

Mas'adi, Ghufron A. Fiqhi Muamalah Kontekstual. Jakarta; Raja Grafindo Persada, 2002. 2009.

Muhammad, Syaikh. Ensiklopedi Islam Kaffah. Surabaya; Pustaka Yassir, 
Munawwir, Ahmad Warsun. Kamus Al-Munawwir: Arab-Indonesia. Surabaya: Pustaka Progressif, 2002.

Muslim Explorer (Islamic Softwere for Al-Quran and Hadits Studies), v.7. Ibnu Majah no. 2420, Kitab al-Ahkam

Pasaribu, Chairumah., \& Suhrawadi K. Lubis, Hukum Perjanjian dalam Islam. Jakarta; Sinar Grafika, 1996.

Qal'ahji, Muhammad Rawwas. Ensiklopedi Fiqhi Umar bin Khathab ra. Jakarta; PT Raja Grafindo Persada, 1999.

Zulhili, Wahbah. Al-Fiqhu Al Islam wa Adillatuhu. terj. Jakarta; PT. BMI, 1999. 